\title{
Gastric Cancer Pathologic TNM Finding v7
}

National Cancer Institute

\section{Source}

National Cancer Institute. Gastric Cancer Pathologic TNM Finding v7. NCI Thesaurus.

Code C89827.

A pathologic finding about one or more characteristics of gastric cancer, following the rules of the TNM AJCC v7 classification system. The pathologic staging depends on data acquired clinically, together with findings on subsequent surgical exploration and examination of the pathologic specimen if resection is accomplished. Pathologic assessment of the regional lymph nodes entails their removal and histologic examination to evaluate the total number, as well as the number that contain metastatic tumor. (from AJCC 7th Ed.) 